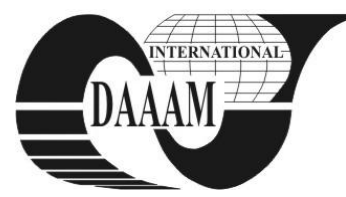

Annals of DAAAM for 2011 \& Proceedings of the 22nd International DAAAM Symposium, Volume 22, No. 1, ISSN 1726-9679 ISBN 978-3-901509-83-4, Editor B. Katalinic, Published by DAAAM International, Vienna, Austria, EU, 2011 Make Harmony between Technology and Nature, and Your Mind will Fly Free as a Bird Annals \& Proceedings of DAAAM International 2011

\title{
UNWINDING FROM CYLINDRICAL PACKAGES
}

\section{PRACEK, S[tanislav]; SLUGA, F[ranci]; MOZINA, K[lemen] \& FRANKEN, G[regor]}

\begin{abstract}
Computer modeling is a valuable tool in the search for the optimal package shape. We demonstrate a mathematical model for simulating the unwinding from cylindrical and conic packages. We show how the winding angle and the apex angle influence the angular velocity of the yarn during the unwinding. Since the centrifugal forces on the yarn in the balloon depend on the angular velocity, this velocity has a large influence on the tension that we wish to reduce.
\end{abstract}

Key words: mathematical model, cylindrical packages, winding angle, yarn unwinding, angular velocity

\section{INTRODUCTION}

The yarn unwinding from packages should proceed at the highest possible unwinding velocity while the yarn tension should remain as low as possible. For this reason it is of utmost importance to determine the package geometry and the winding angle which allow to maximize the unwinding velocity given the allowed highest yarn tensions. In order to be able to compare various package designs it is necessary to determine the influence of the winding angle and the apex angle of the package on the angular velocity of the yarn forming the balloon, since the angular velocity determines to a great extend the yarn tension.

\section{DEPENDENCE OF THE ANGULAR VELOCITY ON THE WINDING ANGLE IN THE CASE OF CYLINDRICAL PACKAGES}

We study the unwinding of yarn from a cylindrical package (Figure 1). The yarn in the layer which is being unwound has a winding angle $\phi$ (Figures 2 and 3). We will show that the winding angle determines the angular velocity $\omega$, if the unwinding velocity $\mathrm{V}$ and the package radius $\mathrm{c}$ are known. The derivation is applicable in the quasi-stationary approximation which consists of neglecting the variation of system parameters (in particular of the winding angle $\phi$ ) during a single period of the balloon motion around the $\mathrm{z}$ axis.

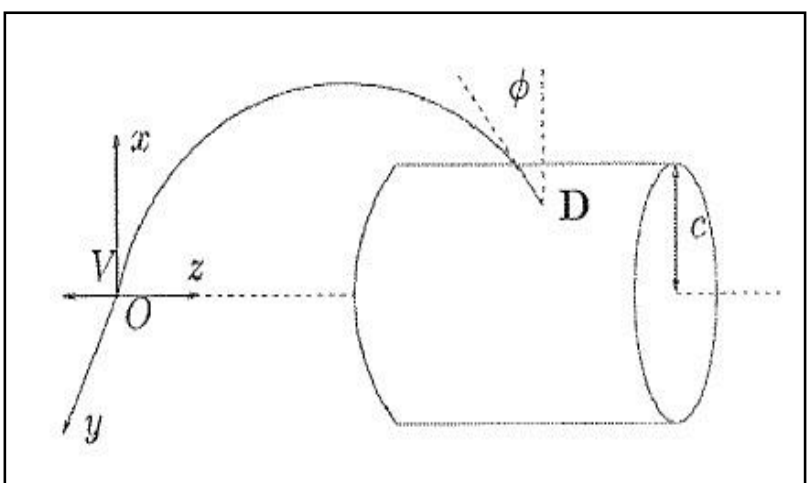

Fig. 1. Yarn unwinding from a cylindrical package
The cylindrical package has radius $\mathrm{c}$ and the yarn is being unwound with velocity $\mathrm{V}$. At the lift-off point $\mathrm{D}$ the yarn leaves the package surfaces and forms the balloon. The angle $\phi$ is the winding angle at the point D (Figure 1).

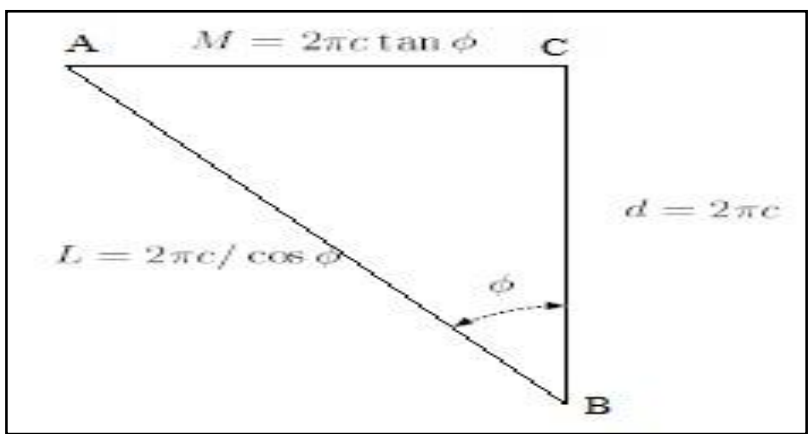

Fig. 2. Unfolded package surfaces; the surface has been cut along the package axis

The winding angle is positive if the lift-off point is moving towards higher values of the coordinate $\mathrm{z}$ during the unwinding (unwinding in the backward direction). The winding angle is negative if the lift-off point is moving towards smaller values of $\mathrm{z}$ (unwinding in the forward direction), see Figure 2.

Let us consider the cylinder unfolded to a plane by cutting the surface along a line parallel to the cylindrical axis, Figure 2. During a single period $t=2 \pi / \omega$ the balloon revolves once around the axis. During the same time the lift-off point likewise makes a single roundtrip around the package: it moves from the point A to the point $B$ on the unfolded cylinder surface. If the lift-off point performed more or less than exactly one full rotation around the package, this would be in contradiction with our assumption of quasi-stationary conditions.

The length of the yarn which unwinds during a single period is therefore equal to $\mathrm{L}=\mathrm{AB}=2 \pi \mathrm{c} / \cos \phi$. The position of the lift-off point on the unfolded cylinder is then $\mathrm{B}$, which is equivalent to the point $\mathrm{C}$ (points $\mathrm{B}$ and $\mathrm{C}$ are actually the same point, if we take into account periodic boundary conditions in the tangential direction of the cylinder surface). Consequently, the lift-off point moves for $\mathrm{M}=\mathrm{AC}=2 \pi \mathrm{ctan} \phi$ along the package surface. In the quasi-stationary approximation we can then interpret this change in the following way: the arc-length of the yarn forming the balloon has increased by M, while the yarn segment with the length L-M has been unwound through the eyelet. The yarn velocity is thus $\mathrm{V}=(\mathrm{L}-\mathrm{M}) / \mathrm{t}$. The angular velocity that we are interested in is therefore

$$
\omega=\frac{2 \pi}{t}=\frac{2 \pi V}{L-M}=\frac{V}{\frac{c}{\cos \phi}-c \tan \phi}=\frac{V \cos \phi}{c(1-\sin \phi)}
$$

Introducing the dimensionless angular velocity $\Omega=\omega \mathrm{c} / \mathrm{V}$, this formula can also be expressed as 


$$
\Omega=\frac{\cos \phi}{1-\sin \phi}
$$

In parallel packages the winding angle is $\phi=0^{\circ}$ and we obtain $\omega=\mathrm{V} / \mathrm{c}$. This is the expected result since in this case the unwinding velocity $\mathrm{V}$ equals the OBODNA velocity of the liftoff point, which is given by $\mathrm{c} \omega$. The dimensionless angular velocity is then $\Omega=1$. Obviously, the winding angle is strictly speaking different from zero even on parallel packages, since a winding angle of exactly zero would imply that the yarn forms a disk. The actual angle $\phi$ can be simply estimated for a closed parallel winding where the winding angle is such that the yarn in each layer forms a dense helix. In a package with radius $\mathrm{c}=200 \mathrm{~mm}$ and yarn diameter $\mathrm{d}=0.2 \mathrm{~mm}$, one obtains $\phi \approx 0.2 / 2 \pi$ $200 \approx 0.01^{\circ}$. With such a winding angle the quantity $\Omega=\cos \phi /(1-$ $\sin \phi)$ differs from 1 on the fourth decimal place. The angle $\phi$ is therefore so small that it can be considered equal to zero for all practical purposes.

Packages with somewhat larger winding angle $\phi$ can also be considered as parallel packages. Real cross-wound packages are those with a winding angle so large that one may observe the characteristic oscillations of the angular velocity during the unwinding and the associated oscillations of the yarn tension (Fraser et al., 1992;Praček \& Jakšić, 2002; Praček, 2002).

The findings can be taken into account when comparing package designs. In parallel packages one has $\Omega=1$. In crosswound packages the parameter $\Omega$ has to be calculated using Eq. (2) for each yarn layer separately. During the unwinding in the forward direction (toward the eyelet) one has $\Omega<1$, while during the unwinding in the backward direction (toward the rear end of the package) one has $\Omega>1$ (Figure 3 ). The results for typical winding angles are shown in Figure 4 and tabulated in table 1.

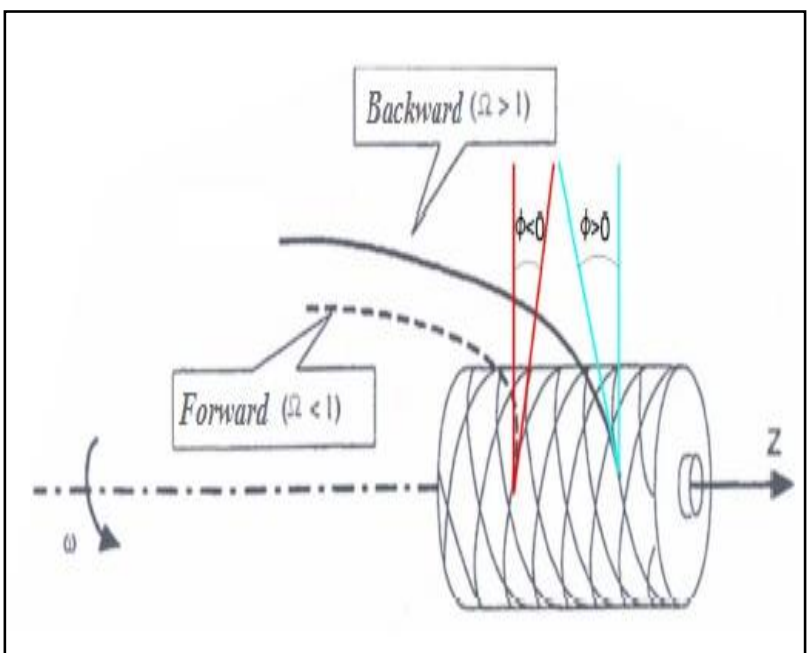

Fig. 3. Dimensionless angular velocity during the unwinding in the backward and forward direction

The dimensionless angular velocity $\Omega$ is larger than 1 during the unwinding in the backward direction and lower than 1 during the unwinding in the forward direction. We now provide an interpretation for this result. Let us imagine that the yarn is being pulled with velocity V. During the unwinding in the forward direction we obtain with each revolution of the liftoff point more yarn than we would obtain from a parallel package. As the unwinding velocity $\mathrm{V}$ is constant, it is possible to unwind yarn from a cylindrical package with a smaller angular velocity than from a parallel package. For this reason the dimensionless angular velocity $\Omega=\mathrm{c} \omega / \mathrm{V}$ is less than 1 . In analogous way one can show that during the unwinding in the backward direction one has $\Omega>1$ (Kong \& Rahn \& Goswami, 1999).

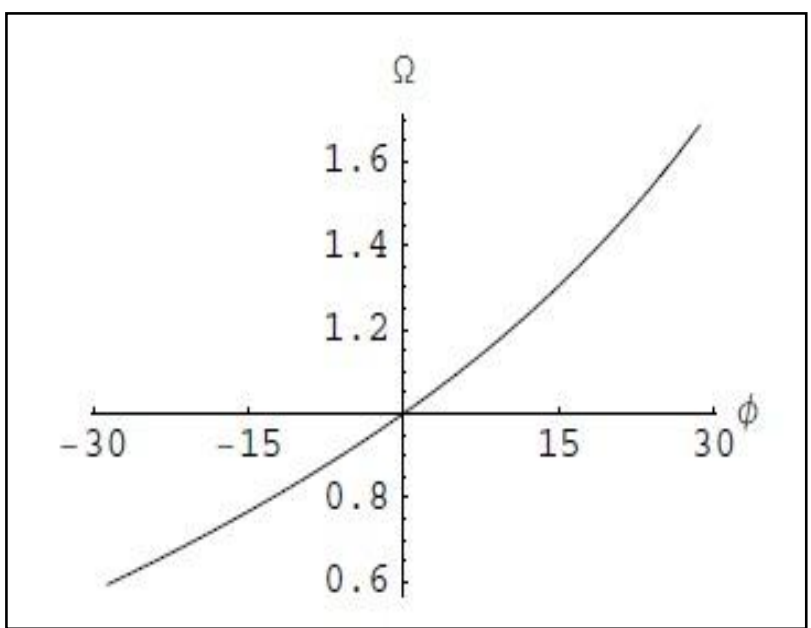

Fig. 4. Dimensionless angular velocity as a function of the winding angle

In Figure 4 we show the dependence of the dimensionless angular velocity $\Omega=\omega \mathrm{c} / \mathrm{V}$ on the winding angle $\phi$. For small angles one finds $\Omega=1$.

\section{CONCLUSION}

For the case of a cylindrical package we have derived the expression which determines the dependence between the angular velocity of the balloon and the various geometrical parameters of the package. We have thereby established that the parallel and the cross-wound packages differ by the absence or presence of the characteristic variations of the angular velocity (and consequently the yarn tension) during the unwinding.

\begin{tabular}{|c|c|c|c|}
\hline Angle $\phi$ & $\begin{array}{l}\Omega \text { at winding } \\
\text { backward }\end{array}$ & Angle $\phi$ & $\begin{array}{l}\Omega \text { at winding } \\
\text { forward }\end{array}$ \\
\hline$\sim 0^{\circ}$ & 1 & $\sim 0^{\circ}$ & 1 \\
\hline $10^{\circ}$ & 1,19 & $-10^{\circ}$ & 0,84 \\
\hline $20^{\circ}$ & 1,42 & $-20^{\circ}$ & 0,70 \\
\hline $30^{\circ}$ & 1,73 & $-30^{\circ}$ & 0,58 \\
\hline $40^{\circ}$ & 2,14 & $-40^{\circ}$ & 0,47 \\
\hline
\end{tabular}

Tab. 1. Dimensionless angular velocity as a function of the winding angle $\phi$

\section{REFERENCES}

Fraser, W. B., Ghosh, T. K., Batra, S. K. (1992). On unwinding yarn from cylindrical package. Proc. R. Soc. Lond. A, 436 $479-498$

Praček, S. (2002). Modification of yarn unwinding dynamics. Dissertation, University of Ljubljana

Praček, S. in Jakšić, D. (2002). Teorija odvijanja preje z navitka - Izpeljava gibalnih enačb. Tekstilec, 45(5-6) 119

Praček, S. in Jakšić, D. (2002). Teorija odvijanja preje z navitka - Robni pogoji in sila zračnega upora. Tekstilec, 45(7-8)

Kong, X. M., Rahn, C. D., Goswami, B. C. (1999). Steadystate unwinding of yarn from cylindrical packages. Text. Res. J., 69, 4, 292-306 